\title{
Research on the Artificial Intelligence Attribution Analysis and the Reasons for Decline of Physical Fitness of College Students in the Tropical Area under the Background of "Sunshine Sports"
}

\author{
Zaichi Cui ${ }^{1}$, Yi Jiang'2,a, Wenting $\mathrm{Hao}^{2}$, Qian Huang ${ }^{3}$ \\ ${ }^{1}$ Department of Physical Education, Hainan Medical College, Haikou, Hainan 571199, China \\ 'School of Physical Education, Hainan Normal University, Haikou, Hainan 571158, China \\ ${ }^{3}$ Haikou Jiangdong Maple Leaf International School, China
}

\begin{abstract}
In 2010, the research team conducted a survey on the physical quality of 1600 college students in Hainan Province, and analyzed the changes in the physical quality of college students in Hainan from 2000 to 2010 , and learned about the impact of sunshine sports on the physical quality of college students in Hainan Province. Based on this, a targeted intervention was proposed, which can provide reference for the sports workers and decision-makers in Hainan Province and improve the physical quality of students.
\end{abstract}

\begin{abstract}
"Sunshine Sports" is an important part of school sports. It is an important measure to enhance students' physical fitness, mental health, and overall development of school sports. Physical fitness is a comprehensive reflection of the functions of various organ systems in the muscle work. It is potentially manifested in people's lives, learning and labor, which is more prominent in physical exercise. Therefore, the study on the effectiveness of sunshine sports on the improvement of college students' physique health level has important practical significance for improving the physique health level of college students and cultivating more outstanding talents and the realization of "Chinese dream" for the socialist modernization of the motherland.
\end{abstract}

\section{Research objects and methods}

\subsection{Research objects}

Select Hainan Province students' physical fitness research points 1600 students aged 19 22 of Hainan Normal University, 100 males, males, urban women and females in each age group.

\subsection{Research methods}

Investigation method: According to the requirements of the "National Student Physical Health Survey and Research Rules", organize professionals to measure the $50 \mathrm{~m}$ running, standing long jump, grip strength, sitting body flexion and endurance quality of each subject and other 5 physical qualities.

Mathematical statistics method: statistical analysis of the data obtained by the survey using software such as SPSS18.0 and Excel 2003, which are widely used in the international social science statistical software.

\section{Research results and analysis}

2.1 Comparison of urban and rural areas and age differences of Hainan college students in 2010

\subsubsection{Speed quality}

\footnotetext{
${ }^{a}$ Corresponding author: Jiang Yi (1983.6-),E-mail: 815146176@qq.com
} 


\begin{tabular}{ccccccccc} 
& $19 \sim 22$ & 400 & 8.29 & 0.76 & 400 & 7.77 & 0.86 & $<0.01$ \\
(female) & 19 & 100 & 9.27 & 1.4 & 100 & 10.42 & 1.9 & $<0.01$ \\
& 20 & 100 & 9.68 & 1.3 & 100 & 9.63 & 1.2 & $>0.05$ \\
& 21 & 100 & 9.30 & 0.6 & 100 & 9.28 & 1 & $>0.05$ \\
& 22 & 100 & 10.47 & 1.1 & 100 & 9.47 & 0.8 & $<0.01$ \\
& $19 \sim 22$ & 400 & 9.68 & 1.1 & 400 & 9.70 & 1.23 & $>0.05$ \\
\hline
\end{tabular}

It can be seen from Table 1 that the average value of $50 \mathrm{~m}$ running in rural boys is less than the mean of urban boys. After $U$ test, the difference of 21 years old is significant $(\mathrm{P}<0.05)$, and the difference of other age groups is not significant $(\mathrm{P}<0.05)$. The average value of urban girls and rural girls is 50 meters, the difference of 19 years old

Table 2. Comparison of strengths of urban and rural college students in Hainan Province in 2010.

\begin{tabular}{|c|c|c|c|c|c|c|c|c|c|}
\hline \multirow[b]{2}{*}{ (index) } & \multirow[b]{2}{*}{$(\operatorname{sex})$} & \multirow[b]{2}{*}{ (age) } & \multicolumn{3}{|c|}{ (urban) } & \multicolumn{3}{|c|}{ (rural) } & \multirow[b]{2}{*}{$\mathrm{P}$} \\
\hline & & & (sample) & (average) & $\begin{array}{l}\text { (Standard } \\
\text { deviation) }\end{array}$ & (sample) & (average) & $\begin{array}{l}\text { (Standard } \\
\text { deviation) }\end{array}$ & \\
\hline \multirow[t]{10}{*}{ (Standing long jump) } & (male) & 19 & 100 & 227.31 & 20.2 & 100 & 229.99 & 20.5 & $>0.05$ \\
\hline & & 20 & 100 & 225.83 & 24.9 & 100 & 221.4 & 31.8 & $>0.05$ \\
\hline & & 21 & 100 & 218.94 & 29 & 100 & 226.12 & 16.9 & $<0.05$ \\
\hline & & 22 & 100 & 222.72 & 23.8 & 100 & 230.3 & 16.6 & $<0.01$ \\
\hline & & $19 \sim 22$ & 400 & 223.7 & 24.5 & 400 & 226.95 & 21.5 & $<0.05$ \\
\hline & (female) & 19 & 100 & 170.94 & 15.6 & 100 & 171.09 & 15.9 & $<0.05$ \\
\hline & & 20 & 100 & 170.41 & 19.9 & 100 & 170.78 & 14.9 & $>0.05$ \\
\hline & & 21 & 100 & 169.98 & 12.7 & 100 & 171.98 & 15.6 & $>0.05$ \\
\hline & & 22 & 100 & 170.44 & 20.4 & 100 & 171.28 & 16.5 & $>0.05$ \\
\hline & & $19 \sim 22$ & 400 & 169.23 & 17.2 & 400 & 171.15 & 15.7 & $>0.05$ \\
\hline \multirow[t]{10}{*}{ (Grip) } & (male) & 19 & 100 & 46.06 & 6.4 & 100 & 40.22 & 8.2 & $<0.01$ \\
\hline & & 20 & 100 & 44.61 & 8 & 100 & 43.22 & 7.3 & $>0.05$ \\
\hline & & 21 & 100 & 43.94 & 7.4 & 100 & 43.16 & 8.4 & $>0.05$ \\
\hline & & 22 & 100 & 45.85 & 7 & 100 & 44.95 & 6.2 & $>0.05$ \\
\hline & & $19 \sim 22$ & 400 & 45.12 & 7.2 & 400 & 42.89 & 7.6 & $<0.01$ \\
\hline & (female) & 19 & 100 & 26.23 & 4.4 & 100 & 27.67 & 5.7 & $<0.05$ \\
\hline & & 20 & 100 & 26.82 & 7.1 & 100 & 26.29 & 6.7 & $>0.05$ \\
\hline & & 21 & 100 & 25.93 & 5 & 100 & 26.42 & 5.9 & $>0.05$ \\
\hline & & 22 & 100 & 25.92 & 7.5 & 100 & 27.95 & 8.8 & $>0.05$ \\
\hline & & $19 \sim 22$ & 400 & 26.22 & 6 & 400 & 27.08 & 6.8 & $>0.05$ \\
\hline
\end{tabular}

It can be seen from Table 2. In terms of standing long jump indicators, the average value of urban boys is smaller than that of rural boys, and the performance of males is better than that of urban males. After U test, the difference of 21 years old is significant $(\mathrm{P}<0.05) .22$ years old was highly significant $(\mathrm{P}<0.01)$, and the difference between the 19 and 20 age groups was not

was significant $(\mathrm{P}<0.05)$, the difference of 22 years old was highly significant $(\mathrm{P}>0.01)$, and the difference of other age groups was not significant $(\mathrm{P}>0.05)$.

\subsubsection{Strength quality}

significant $(\mathrm{P}>0.05)$.As far as the grip index is concerned the average value of urban boys is higher than that of rural boys. According to $U$ test, the difference of 19 years old is highly significant $(\mathrm{P}<0.01)$, and the urban-rural difference of 20-22 years is not significant $(\mathrm{P}>0.05)$.

\subsubsection{Endurance quality}

Table 3. Comparison of $1000 \mathrm{~m} / 800 \mathrm{~m}$ results of urban and rural college students in Hainan Province.

\begin{tabular}{ccccccccc}
\hline & & \multicolumn{5}{c}{ urban } & \multicolumn{3}{c}{ rural } & \multirow{2}{*}{ sex } & age & sample & average & $\begin{array}{c}\text { Standard } \\
\text { deviation }\end{array}$ & sample & average & $\begin{array}{c}\text { Standard } \\
\text { deviation }\end{array}$ & P \\
\cline { 3 - 7 } male & 19 & 100 & 251.48 & 29.1 & 100 & 250.26 & 28.5 & $>0.05$ \\
& 20 & 100 & 247.51 & 29.8 & 100 & 250.42 & 26 & $>0.05$ \\
& 21 & 100 & 279.78 & 30 & 100 & 259.88 & 38.4 & $<0.01$ \\
& 22 & 100 & 261.19 & 35.2 & 100 & 254.75 & 30.5 & $>0.05$
\end{tabular}




\begin{tabular}{ccccccccc} 
& $19 \sim 22$ & 400 & 259.99 & 31.1 & 400 & 253.83 & 30.9 & $<0.01$ \\
female & 19 & 100 & 226.79 & 52.8 & 100 & 245.34 & 22.2 & $<0.01$ \\
& 20 & 100 & 251.86 & 22.3 & 100 & 248.43 & 23.5 & $>0.05$ \\
& 21 & 100 & 252.47 & 26.8 & 100 & 246.60 & 26 & $>0.05$ \\
22 & 100 & 251.34 & 23.1 & 100 & 248.54 & 23.3 & $>0.05$ \\
& $19 \sim 22$ & 400 & 245.62 & 31.3 & 400 & 247.23 & 23.8 & $>0.05$ \\
\hline
\end{tabular}

It can be seen from Table 3 that the average value of urban male students running 1000 meters is higher than that of rural male students. The results of rural male students are better than urban male students. According to the $U$ test, except for the urban-rural difference of 20 years old, the difference between urban and rural areas is highly significant $(\mathrm{P}<0.01)$. The age group was not significant $(\mathrm{P}>0.05)$. The average value of urban girls' 800-meter running is lower than that of rural boys. Urban girls' cities are better than rural girls. According to U-test, except for the 19-year-old urban-rural difference $(\mathrm{P}<0.01)$, the other age groups are not significant $(\mathrm{P}>0.05)$.

\subsubsection{Flexibility}

Table 4. Comparison of the positional flexion index of urban and rural college students in Hainan Province.

\begin{tabular}{ccccccccc}
\hline & & \multicolumn{5}{c}{ urban } & \multicolumn{3}{c}{ rural } & \\
\cline { 3 - 6 } sex & age & sample & average & $\begin{array}{c}\text { Standard } \\
\text { deviation }\end{array}$ & sample & average & $\begin{array}{c}\text { Standard } \\
\text { deviation }\end{array}$ & P \\
\cline { 2 - 6 } male & 19 & 100 & 14.56 & 6.6 & 100 & 14.67 & 6.4 & $>0.05$ \\
& 20 & 100 & 11.67 & 6 & 100 & 12.27 & 6.2 & $>0.05$ \\
& 21 & 100 & 16.65 & 6.3 & 100 & 14.68 & 6.6 & $<0.05$ \\
& 22 & 100 & 12.23 & 8 & 100 & 13.75 & 5.5 & $>0.05$ \\
female & $19 \sim 22$ & 400 & 13.78 & 6.7 & 100 & 13.85 & 6.2 & $>0.05$ \\
& 19 & 100 & 17.28 & 5.9 & 100 & 18.67 & 5.5 & $>0.05$ \\
& 20 & 100 & 15.89 & 5.6 & 100 & 16.19 & 5.6 & $>0.05$ \\
& 21 & 100 & 15.21 & 5.8 & 100 & 16.43 & 4.9 & $>0.05$ \\
& 22 & 100 & 17.66 & 5.2 & 100 & 16.36 & 5.6 & $>0.05$ \\
& $19 \sim 22$ & 400 & 16.83 & 5.6 & 100 & 16.93 & 5.4 & $>0.05$
\end{tabular}

As shown in Table 4, the average value of urban boys is lower than that of rural boys. According to the $U$ test, except for the difference between urban and rural areas of 21 years old, the difference between urban and rural areas is highly significant $(\mathrm{P}<0.01)$, and the urban-rural differences of other age groups are not significant $(\mathrm{P}>$ $0.05)$. The average value of rural girls is higher than that of urban girls. According to the $U$ test, the differences between the 19-22 age groups are not significant $(\mathrm{P}>0.05)$.

\subsection{Comparative analysis of the physical quality indicators of college students in Hainan Province and similar indicators in 2005 and 2000}

Table 5 Comparison of the Physical Fitness of College Students in Hainan Province from 2000 to 2010.

\begin{tabular}{cccccccccc}
\hline sex & type & 2000 mean & 2005 mean & 2010 mean & $\mathrm{d} 1$ & $\mathrm{U} 1$ & $\mathrm{~d} 2$ & $\mathrm{U} 2$ \\
\hline male & 50metre & 7.17 & 7.59 & 8.03 & 0.42 & $16.52^{* *}$ & 0.44 & $17.83^{* *}$ \\
& Standing long jump & 251.53 & 225.1 & 225.33 & -26.43 & $19.12^{* *}$ & 0.23 & 0.17 \\
& Grip & 38.3 & 40.44 & 44.05 & 2.14 & $5.83^{* *}$ & 3.51 & $10.38^{* *}$ \\
& 1000/800metre & 224 & 250.53 & 256.91 & 26.53 & $16.47^{* *}$ & 6.38 & $4.02^{* *}$ \\
& Sitting body flexion & 13.3 & 14.53 & 13.82 & 1.23 & $4.35^{* *}$ & -0.71 & $2.14^{*}$ & 0.28 \\
female & 50metre & 8.58 & 9.7 & 9.69 & 1.12 & $30.67^{* *}$ & 0.01 & & \\
& Standing long jump & 191.13 & 165.34 & 170.19 & -25.79 & $26.18^{* *}$ & 4.85 & $5.54^{* *}$ \\
& Grip & 24.77 & 24.78 & 26.65 & 0.01 & 0.04 & 1.87 & $6.75^{* *}$ & $7.84^{* *}$ \\
& 1000/800metre & 223.12 & 258.35 & 246.43 & 35.23 & $20.98^{* *}$ & -11.92 & 1.03 \\
\hline
\end{tabular}

Note:** refers to $\mathrm{P}<0.01 ; *$ refers to $\mathrm{P}<0.05 ; \mathrm{D} 1$ is the difference between 2005 and $2000 ; \mathrm{d} 2$ is the difference between 2010 and 2005 
Through the development trend of Hainan college students' physical fitness from 2000 to 2010, it can be seen that the male students' 50-meter performance has decreased year by year, male and female college students have set a long-term decline in the first five years. The annual increase, and the increase of female students is more obvious; the male and female grip strength indicators are increasing year by year, the male students' 1000 meters index is decreasing year by year, but the decline in the next five years is lower than the previous five years, girls The 800-meter indicator rose five years after the decline in the previous five years; the male seated flexion index fell five years after the five-year increase, and the female student increased year by year, but the increase in the next five years was significantly less than the previous five years.

\section{Intervention strategies and conclusions}

\subsection{Intervention strategy}

3.1.1 In implementing the spirit of the document, all colleges and universities should seek truth from facts and adapt to local conditions. According to the actual situation faced in their own school sports work, they should do a good job in physical education classroom teaching. At the same time, we will actively promote extracurricular sports activities for students, and regularly carry out sports and sports activities such as sports festivals and sports games.

3.1.2 "School sports work should take "National Hundreds of Million Students Sunshine Sports" as a breakthrough in the development and innovation of school sports work and the support of students' physical fitness test, and actively promote students through the Sunshine Sports series activities. "Sports is happiness, life is sports" awareness. Let students enjoy the sports activities that can bring happiness in life and actively participate in physical exercise, so that the call of "exercising one hour a day, healthy work for fifty years, and a happy life for a lifetime" becomes a kind of student learning life. Health awareness guide.

3.1.3 The teaching content of college physical education curriculum should meet the diversified needs of students, and actively promote the "three independent" teaching forms of students' self-selected curriculum content, teaching teachers and teaching time. Encourage students to participate in physical exercise, develop a good attitude of physical exercise and consciously participate in physical exercise, and establish a "health first" lifelong sports concept.

\section{References}

1. Hao Wenting. Research on Physical Health of Students in Hainan Province (College Social Science Library) [M]. Guangming Daily Press, June 2010.

2. Jia Xiuwen. Investigation and Analysis of College Students' Physical Fitness Status in Shanxi Province [J]. Journal of Beijing Sport University, 2002, 25(6): 731-734.

3. $\mathrm{Xu}$ Jianguo. Study on the Current Situation and Countermeasures of Physical Health of Pupils in Suzhou City [J]. Journal of Changchun University, 2011, 21(2): 89-92.

4. Hao Wenting, Zhang Yaling. Investigation and Comparative Analysis of Body Shapes of Li and Han Nationality Students in Hainan [J]. Journal of Beijing Sport University, November 2006.

5. Dong Xinjun. Analysis of the Effectiveness of Sunshine Sports on College Students' Physical Health Improvement $[\mathrm{J}]$. Journal of Jiangsu Teachers University of Technology, 2011, 17(4). 